ORNL/TM-2014/483

\title{
Improving Heat Pump Water Heater Efficiency by Avoiding Electric Resistance Heater Use
}

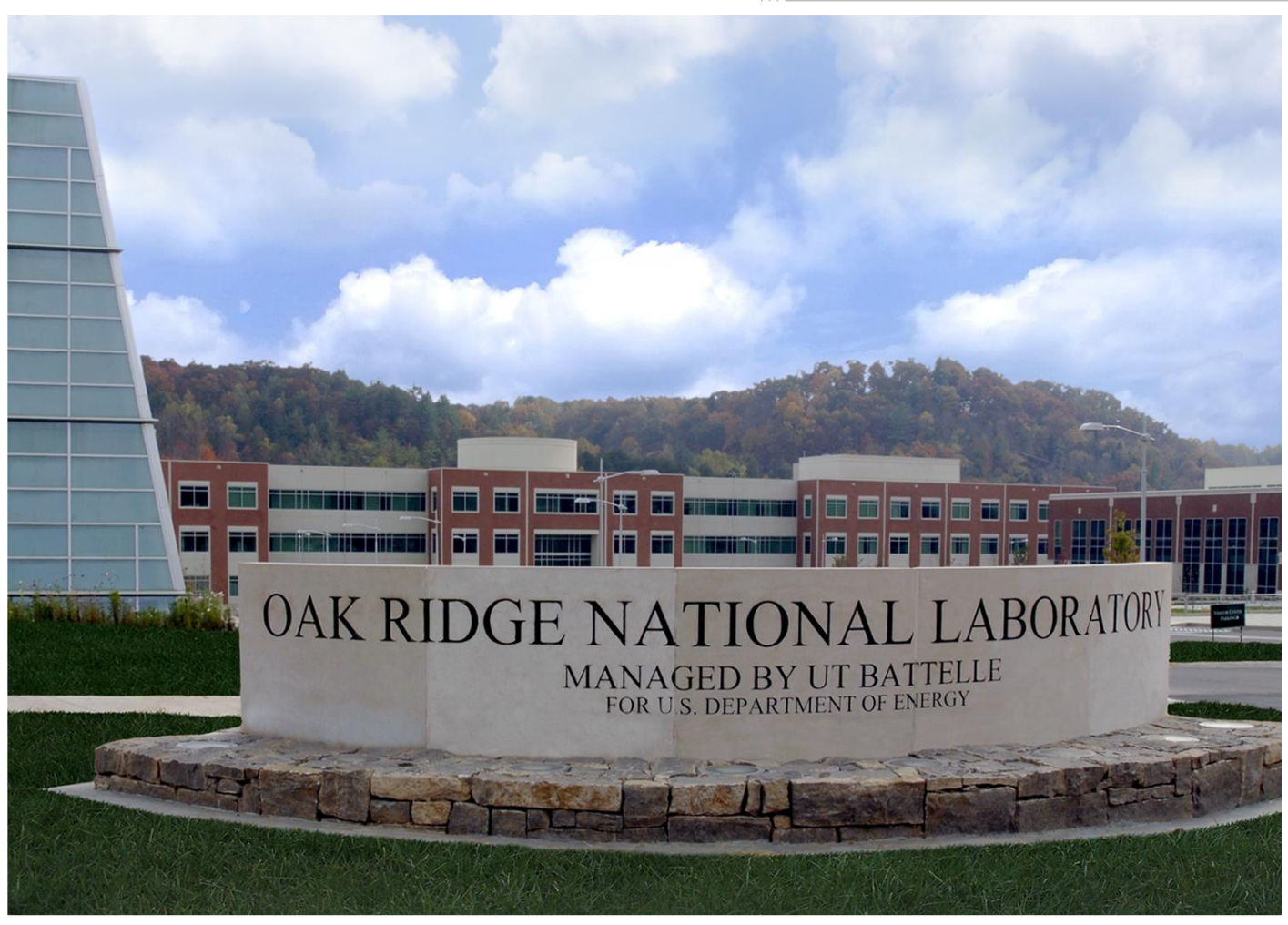

Approved for public release. Distribution is unlimited.
Philip Boudreaux Jeffrey Munk Roderick Jackson Anthony Gehl April Parkison James Nutaro

September 2014 


\section{DOCUMENT AVAILABILITY}

Reports produced after January 1, 1996, are generally available free via US Department of Energy (DOE) SciTech Connect.

Website http://www.osti.gov/scitech/

Reports produced before January 1, 1996, may be purchased by members of the public from the following source:

National Technical Information Service

5285 Port Royal Road

Springfield, VA 22161

Telephone 703-605-6000 (1-800-553-6847)

TDD 703-487-4639

Fax 703-605-6900

E-mail info@ntis.gov

Website http://www.ntis.gov/help/ordermethods.aspx

Reports are available to DOE employees, DOE contractors, Energy Technology Data Exchange representatives, and International Nuclear Information System representatives from the following source:

Office of Scientific and Technical Information

PO Box 62

Oak Ridge, TN 37831

Telephone 865-576-8401

Fax 865-576-5728

E-mail reports@osti.gov

Website http://www.osti.gov/contact.html

This report was prepared as an account of work sponsored by an agency of the United States Government. Neither the United States Government nor any agency thereof, nor any of their employees, makes any warranty, express or implied, or assumes any legal liability or responsibility for the accuracy, completeness, or usefulness of any information, apparatus, product, or process disclosed, or represents that its use would not infringe privately owned rights. Reference herein to any specific commercial product, process, or service by trade name, trademark, manufacturer, or otherwise, does not necessarily constitute or imply its endorsement, recommendation, or favoring by the United States Government or any agency thereof. The views and opinions of authors expressed herein do not necessarily state or reflect those of the United States Government or any agency thereof. 
Building Technologies Research and Integration Center

\title{
IMPROVING HEAT PUMP WATER HEATER EFFICIENCY BY AVOIDING ELECTRIC RESISTANCE HEATER USE
}

\author{
Philip Boudreaux \\ Jeffrey Munk \\ Roderick Jackson \\ Anthony Gehl \\ April Parkison \\ James Nutaro
}

Date Published: September 2014

\author{
Prepared by \\ OAK RIDGE NATIONAL LABORATORY \\ Oak Ridge, Tennessee 37831-6283 \\ managed by \\ UT-BATTELLE, LLC \\ for the \\ US DEPARTMENT OF ENERGY \\ under contract DE-AC05-00OR22725
}





\section{CONTENTS}

Page

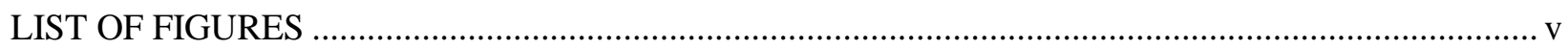

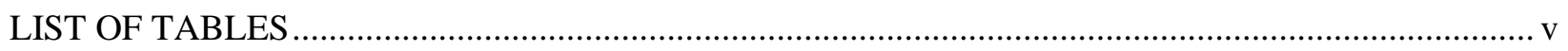

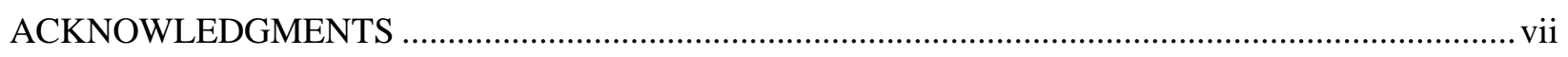

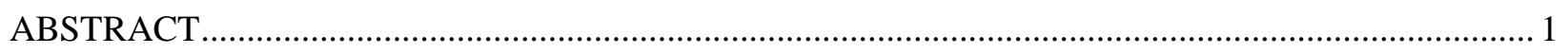

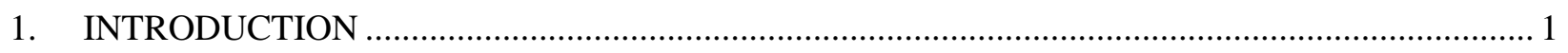

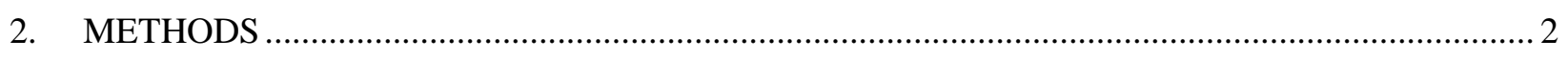

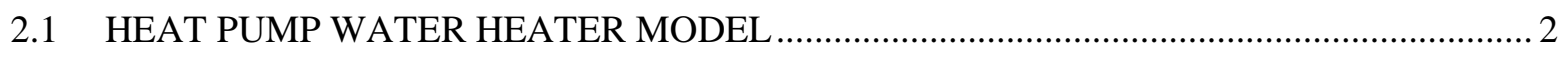

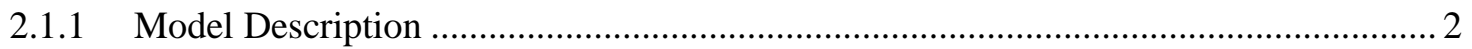

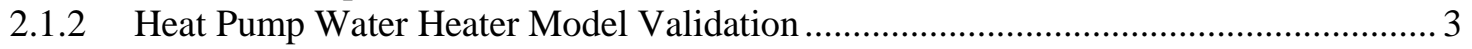

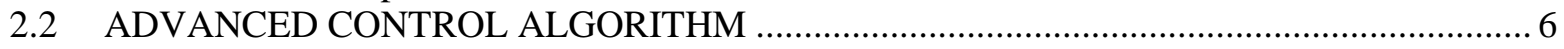

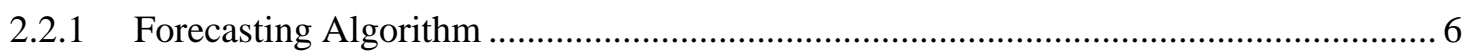

2.2.2 Temperature Set-Point Algorithm................................................................ 9

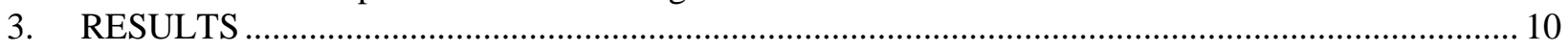

3.1 INITIAL TESTING OF ADVANCED CONTROL ALGORITHM USING

COMPUTER SIMULATIONS ................................................................................... 10

3.2 ANALYSIS OF 25 HOMES FOR HPWH SAVING USING THE ORNL ADVANCED

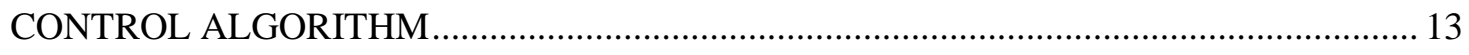

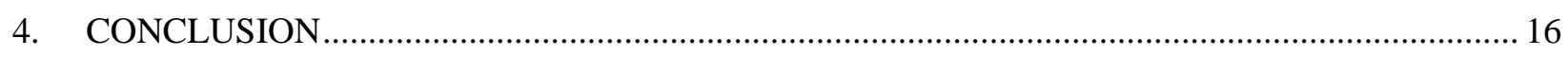

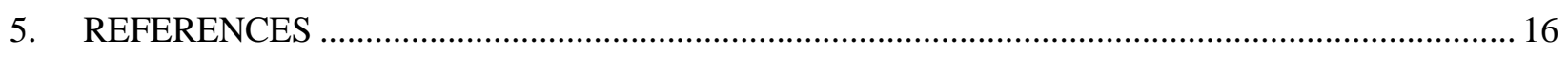

APPENDIX A. RESULTS FROM 25-HOME STUDY …................................................................ A-1 



\section{LIST OF FIGURES}

Figure

1. Comparison of measured and modeled daily and minute water heater energy

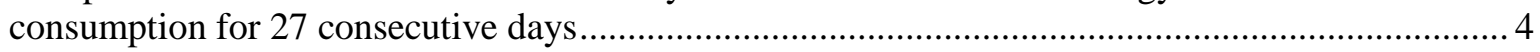

2. Modeled data compared to measured water heater data for day with electric

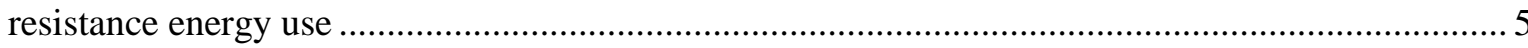

3. Modeled data compared to measured water heater data for day with only

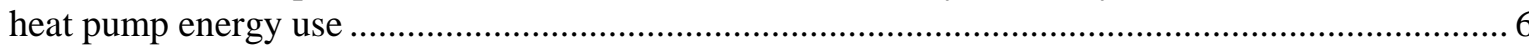

4. Example of dependent flow data with independent metadata such as month, day, day of week, season, and time of day ......................................................................... 7

5. Example of General Systems Problem Solver data flow ........................................................... 8

6. Actual and predicted hourly flow when 20 gal or more …........................................................ 8

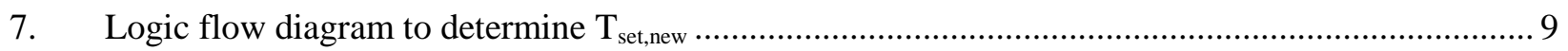

8. Illustration of how the final temperature set-point schedule is computed ...................................... 10

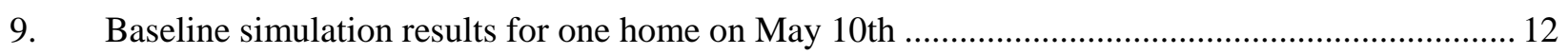

10. Advanced control algorithm simulation results for one home on May 10th................................ 12

11. Average energy consumption of the baseline, advanced control, and perfect prediction cases for a set of 25 homes

12. Histogram of advanced control algorithm (forecasted) energy savings results compared to perfect prediction energy savings results

13. Advanced control algorithm energy savings plotted as a function of the coefficient of variation of the root mean square error (CV-RMSE) of forecasted water draw volume

14. Advanced control algorithm savings plotted as a function of baseline yearly electric resistance energy consumption

\section{LIST OF TABLES}

Table

1. Results from initial testing of advanced control algorithm on one home .................................... 11

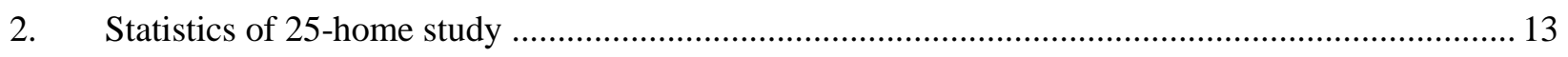





\section{ACKNOWLEDGMENTS}

The authors would like to thank David Dinse of the Tennessee Valley Authority who sponsored the Campbell Creek homes where some of this research was completed. The authors also appreciate the water heater flow data offered by Ben Larson and Jeffrey Uslan of Ecotope that was used in the heat pump water heater simulations. Assistance from Timothy Scott Shaffer, Mike Beyerle, and Corey Sweatt from General Electric was also greatly appreciated. 



\begin{abstract}
Heat pump water heaters (HPWHs) are a promising technology that can decrease domestic hot water energy consumption by more than $50 \%$ compared with electric resistance storage water heaters. Hybrid HPWHs are really two water heaters in one; they can heat water by using a heat pump or by using electric resistance elements. During large water draw events the HPWHs will use the resistance elements that decrease the overall efficiency of the units. The Oak Ridge National Laboratory team proposed and tested an advanced control algorithm that anticipates the large water draw events and appropriately raises the temperature of the tank water using only the heat pump. With sufficient energy stored in the tank at the elevated temperature, electric resistance use is avoided for large water draws. Simulations using a validated HPWH model and measured water draw data from 25 homes, show average yearly energy savings of $9 \%$ for the advanced control algorithm. If the advanced control algorithm perfectly predicts the large water draw events, the savings increase to $19 \%$. This discrepancy could be due to a lack of predictability of water draw patterns in some homes or a needed improvement in the water draw forecasting algorithm.
\end{abstract}

\title{
1. INTRODUCTION
}

Water heating is the second largest energy consuming end use in the residential buildings sector after space conditioning (BTP 2012). Heat pump water heaters (HPWHs) are a promising technology with energy savings of more than 50\% compared with electric resistance storage water heaters (Hudon 2012). The hybrid HPWH heats water using two different methods. When hot water demand is low a heat pump is used, which moves heat from the air around the unit to the water in the tank. During high water demand events the HPWH behaves like an electric resistance storage unit, which uses electric elements to quickly bring the water back to the set-point temperature because the heat pump is relatively slow in heating water.

A team from Oak Ridge National Laboratory (ORNL) investigated whether the efficiency of the HPWH could be improved by avoiding the use of electric resistance elements, which are not as efficient as the heat pump alone. This approach requires an advanced control algorithm-one that would predict large water draw events and raise the temperature of the tank appropriately, using only the heat pump, in anticipation of the large water draw. In this scenario, the energy used by the heat pump to increase the tank water temperature is less than if the tank had to recover using electric resistance heating.

To investigate this advanced control algorithm ORNL created an HPWH computer model in MATLAB. With time series inputs of incoming cold water temperature, outgoing hot water temperature, ambient temperature, and water draw volume, the model yields the power draw of the water heater on a 1 min basis. This model was validated using real data from the Campbell Creek Research Homes (Christian 2010). After the model was validated it was used to test the advanced control algorithm.

The advanced control algorithm has two parts. The first part is a forecasting algorithm that predicts the flow pattern for the upcoming day based on a historical window of water draw data. The second part of the algorithm is a tank temperature set-point algorithm that computes the appropriate temperature set-point schedule for the upcoming day on an hourly basis so that no electric resistance will be used.

In this report, the HPWH model is described and the model validation is presented. The forecasting algorithm and temperature set-point algorithm are also presented in detail. Finally, energy savings results are presented for simulations of 25 homes using the advanced control algorithm. 


\section{METHODS}

\subsection{HEAT PUMP WATER HEATER MODEL}

\subsubsection{Model Description}

To test the advanced control algorithm a simple one dimensional HPWH model was built in MATLAB. This model simulates energy consumption of the unit based on water draw, ambient air temperature, incoming water temperature, and temperature set point. The model uses the manufacturer's logic to determine when the heat pump or electric resistance heat is used. This model is used to find the baseline energy consumption and the advanced control energy consumption. These energies are compared to determine the possible savings of the advanced control algorithm. The specific unit that was modeled for this research has the condenser from the heat pump wrapped around the bottom half of the water tank and two electric elements, one at the top of the tank and the other at the bottom. Hot water is drawn from the top of the tank, and cold water is added at the bottom of the tank.

The model that was created splits the water tank into six equal volumes and calculates the uniform change in temperature of each volume node every minute. The change in temperature is calculated based on heat added to the tank from the heat pump or a resistance element, heat lost to the ambient environment through the tank walls, and water draws. In general, the temperature change per time step of a node (N) is given by the following equation. Note that there is no conductive heat transfer between nodes in the equation. Also note that for each node there is no radial temperature change; each node is considered to have a homogeneous temperature.

$$
\frac{\Delta T(N)}{\Delta t}=\frac{E_{H P, \text { Element }} * C(N)-U A(N) *\left(T_{w}(N)-T_{a m b}\right)-\dot{m} * c_{p} *\left(T_{w}(N)-T_{w}(N+1)\right)}{c_{p} * m(N)}
$$

Where

$E_{H P, E l e m e n t}=$ Energy added to tank by the heat pump or elements [Btu],

$C(N) \quad=\quad$ fraction of energy added to node (see below),

$U A(N)=$ standby heat loss coefficient of node $\mathrm{N}\left[\mathrm{Btu} / \mathrm{min}{ }^{\circ} \mathrm{F}\right]$,

$T_{w}(N) \quad=$ Water temperature of node $\mathrm{N}\left[{ }^{\circ} \mathrm{F}\right]$,

$T_{a m b} \quad=$ ambient temperature $\left[{ }^{\circ} \mathrm{F}\right]$,

$\dot{m} \quad=$ mass flow rate $[\mathrm{lb} / \mathrm{min}]$,

$c_{p} \quad=$ Specific heat of water $\left[\mathrm{Btu} / \mathrm{lb}{ }^{\circ} \mathrm{F}\right]$,

$T_{w}(N+1)=$ Water temperature of node $\mathrm{N}+1\left[{ }^{\circ} \mathrm{F}\right]$,

$m(N) \quad=$ mass of water in node $\mathrm{N}[\mathrm{lb}]$.

The energy added to the tank by the heat pump or elements, $E_{H P}$, is calculated using an empirically derived formula and is a function of ambient temperature and average tank temperature. When the heat pump is on, the following equation is used to determine how much of the energy is added to each node. This equation is adapted from a presentation, "Heat Pump Water Heater-Quick Simulation Approach," by Larson and Logsdon (Larson 2013). When the electric elements turn on the energy is split equally among the top five or bottom five nodes for the upper and lower elements respectively.

$$
C(N)=\frac{1}{1+e^{\frac{T_{w}(N)-T_{w}(6)}{3.7}-5}}\left(T_{\text {set }}-T_{w}(N)\right)
$$


The model controls the elements and heat pump based on an average of the top two node temperatures plus a small fraction of cold makeup water temperature (if a water draw is occurring during the time step) to account for flow through the anti-siphon hole in the cold water dip tube, which most closely matches how the actual unit is controlled. After this temperature is compared to the set-point temperature the model uses the same logic as the real unit to determine whether there is a demand for heating and which heating apparatus to use.

\subsubsection{Heat Pump Water Heater Model Validation}

The model described above was validated by using 1 min resolution hot water flow and cold water temperature and ambient air temperature data from a real house with a General Electric GeoSpring Hybrid Water Heater (Boudreaux 2012). The model output was then compared to the measured energy consumption and node temperatures. This was done for a data set of 27 consecutive days. Figure 1 shows the results for daily energy consumption and for minute energy consumption. The coefficient of variation of the root mean square error (CV-RMSE) for the daily data is $\pm 7 \%$, and the normal mean bias error $(\mathrm{NMBE})$ is $+2 \%$. These metrics give a good indication of the prediction uncertainty of the model. Better prediction uncertainty is indicated by lower values. These prediction metrics are better than the hourly and monthly standards set forth in ASHRAE Guideline 14, which are $\pm 30 \%$ and $\pm 15 \%$, respectively, for the CV-RMSE and $\pm 10 \%$ and $\pm 5 \%$ for the NMBE (ASHRAE 2002). The total modeled energy

consumption for these 27 days was only $1.5 \%$ less than the measured data. Notice in the minute data that there were two instances that the model did not turn on the electric resistance heat, which explains why the model underpredicted the energy consumption. The measured water flow and tank temperature do not warrant the electric resistance heat according to the control logic from the manufacturer for these two instances, so it is unclear why this occurred. However, this may be due to some slight discrepancies between the unit's temperature sensor and the temperature sensor added for data collection. 

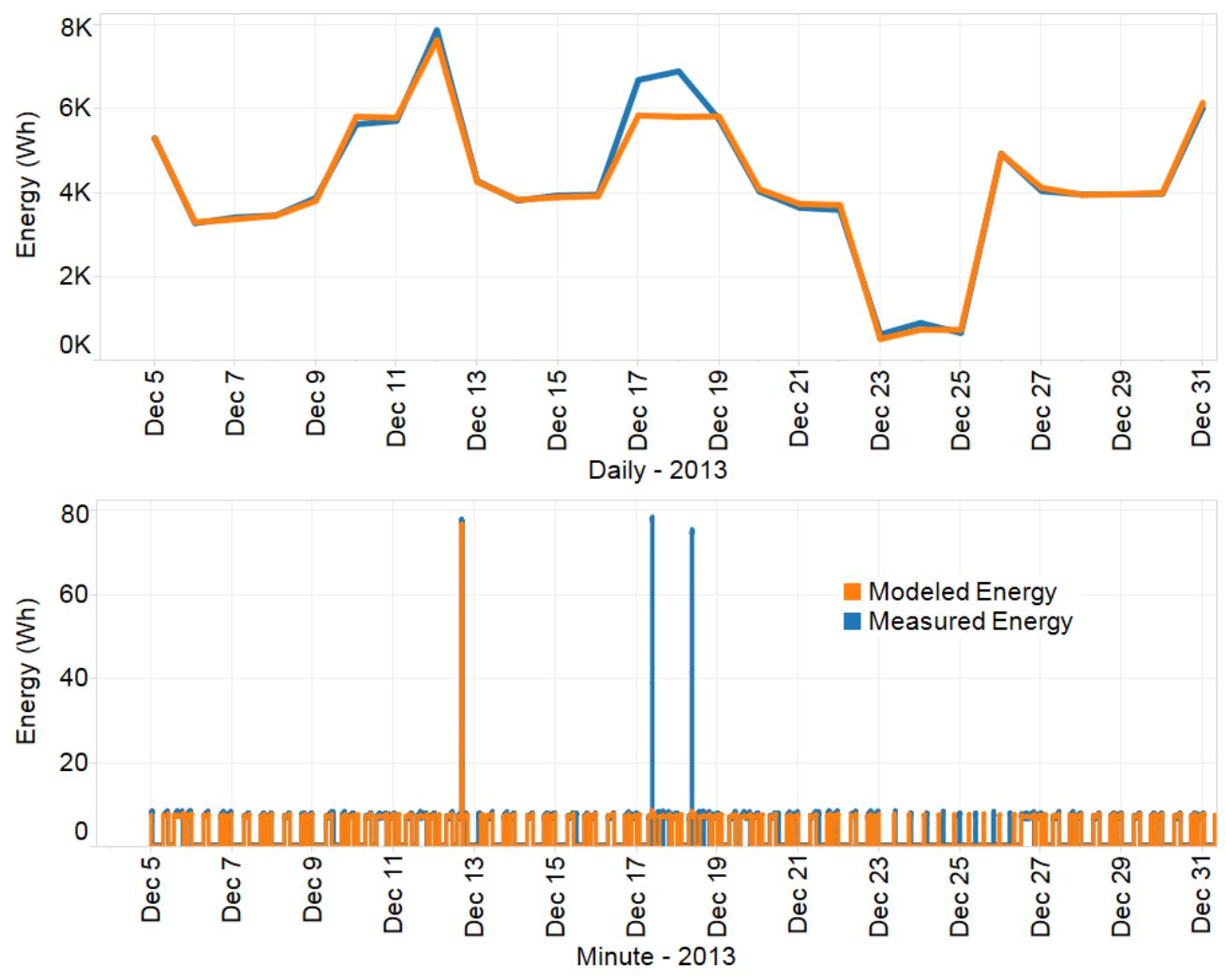

Fig. 1. Comparison of measured and modeled daily and minute water heater energy consumption for 27 consecutive days. As can be seen in the upper plot, the daily hot water use of the occupants of this home is not consistent.

Figures 2 and 3 each show a day of interest within the 27-day data set. Figure 2 shows a comparison of energy and top and bottom node temperature between the model and measured data for December 12, 2013. For this day the electric resistance heat was used. The daily modeled energy consumption was $3 \%$ less than the measured daily HPWH energy use.

Figure 3 shows a comparison of energy and top and bottom node temperature between the model and measured data for December 22, 2013. For this day the heat pump was used exclusively. The daily modeled energy consumption was $3.2 \%$ more than the measured daily HPWH energy use. 

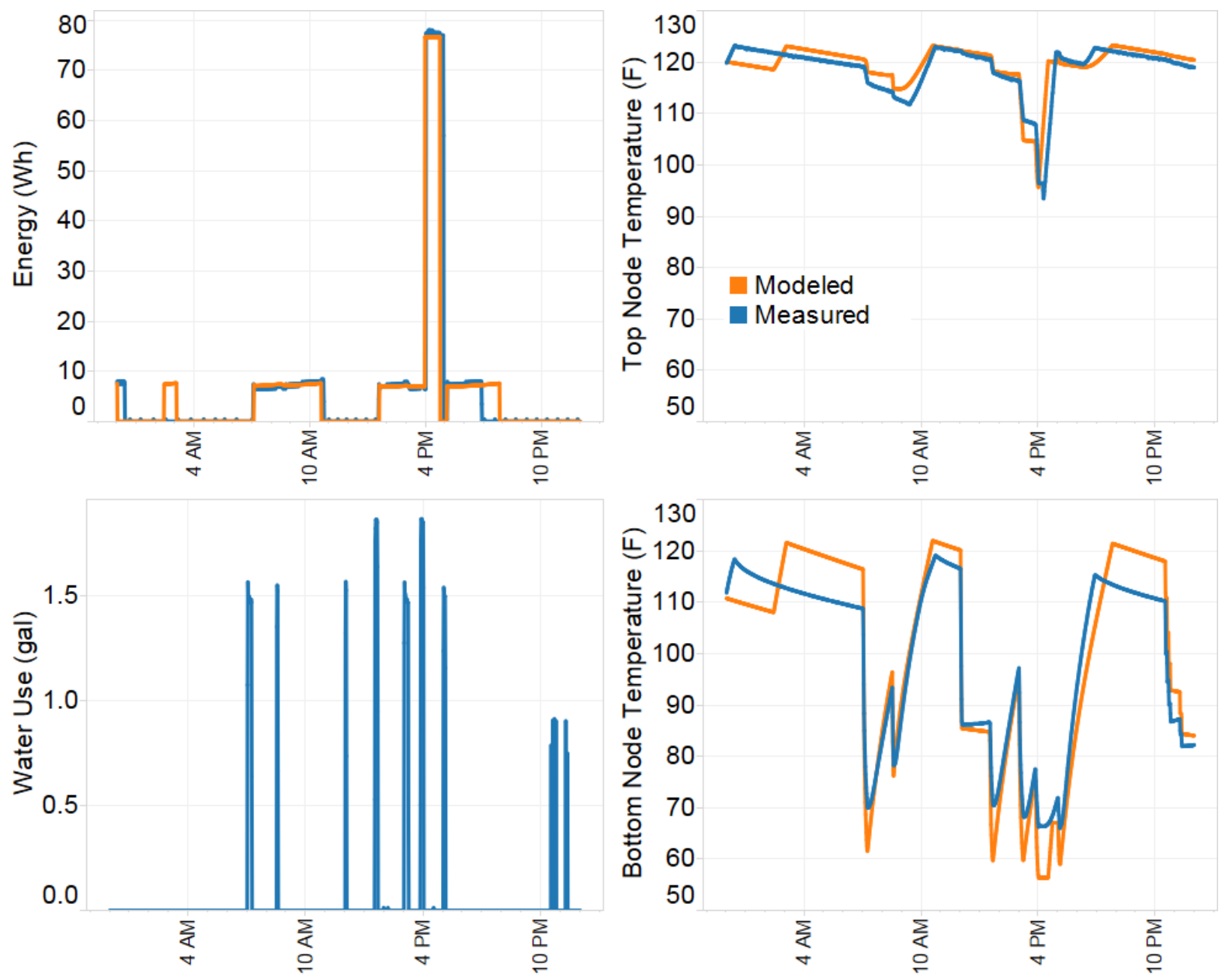

Fig. 2. Modeled data compared to measured water heater data for day with electric resistance energy use. 

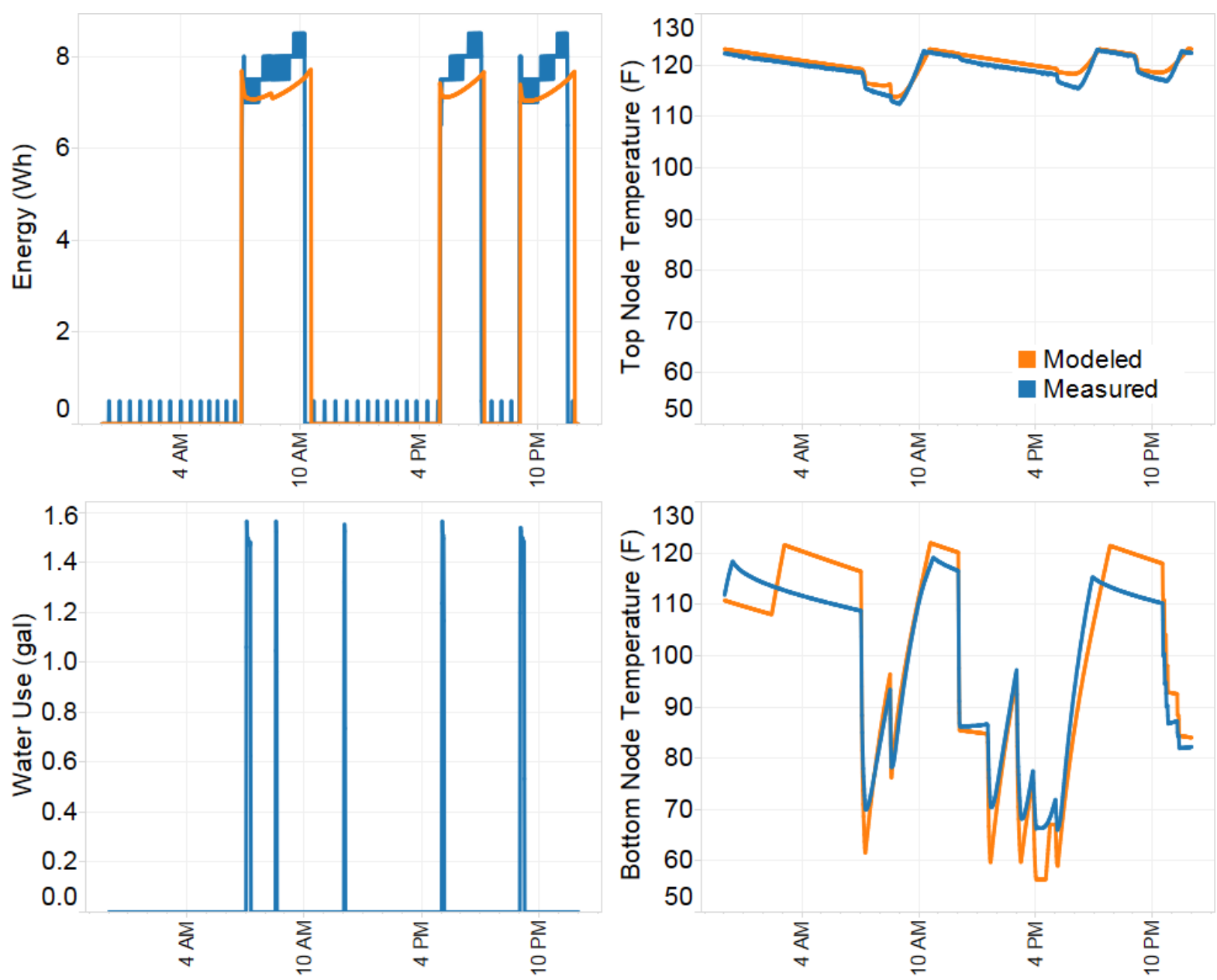

Fig. 3. Modeled data compared to measured water heater data for day with only heat pump energy use.

\subsection{ADVANCED CONTROL ALGORITHM}

To avoid using electric resistance energy requires two steps. The first step is to predict the hot water use pattern for a period of time in the future. To achieve this, a forecasting algorithm was developed. The second step is to adjust the temperature set point based on the forecasted hot water draws so that no electric resistance heat will be used. To achieve this step a temperature set-point algorithm was developed. Both algorithms will be described below.

\subsubsection{Forecasting Algorithm}

To predict future water draws a computer program developed at ORNL called the General Systems Problem Solver (GSPS) was used; this software realizes the modeling algorithms described by Klir and Elias (2003). For this project the program was set up to choose the most likely value of water draw volume for a given time and day (weekend or weekday) based on a set of historical data. Following is an example of how the GSPS forecasts demand for hot water.

The GSPS first needs a historical window of data, an example of which is shown in Fig. 4. Typically a historical window of 3-9 weeks is needed to predict what will happen the next day. As seen in Fig. 4, water draw volume is connected to metadata such as month, day, day of week, season, and time of day. 


\begin{tabular}{|l|l|l|l|l|l|} 
Month & \multicolumn{2}{l}{ Day of Month } & Day & Season & \multicolumn{2}{l|}{ Time of Day } & Water Volume \\
\hline 1 & 21 & Friday & Winter & $0: 00$ & 0.1 \\
\hline 1 & 21 & Friday & Winter & $0: 15$ & 0.0 \\
\hline 1 & 21 & Friday & Winter & $0: 30$ & 0.0 \\
\hline 1 & 21 & Friday & Winter & $0: 45$ & 0.0 \\
\hline 1 & 21 & Friday & Winter & $1: 00$ & 0.0 \\
\hline 1 & 21 & Friday & Winter & $1: 15$ & 0.0 \\
\hline 1 & 21 & Friday & Winter & $1: 30$ & 0.0 \\
\hline 1 & 21 & Friday & Winter & $1: 45$ & 0.0 \\
\hline 1 & 21 & Friday & Winter & $2: 00$ & 0.0 \\
\hline
\end{tabular}

Fig. 4. Example of dependent flow data with independent metadata such as month, day, day of week, season, and time of day.

The historical data are entered into the GSPS and organized based on metadata that are most correlated to the variable of interest. For this example the water draw volume is the variable of interest and is organized as a function of day of week and time of day (in 15 min intervals). The program determines the number of occurrences and the probability that each water draw volume happens throughout the historical window based on the day of week and time of day as shown in the left-most chart in Fig. 5. Then a filter is set to ignore water draw volumes that are below a certain number of occurrences or probability. In this example, anything that happened only once was ignored, and the resulting water draws are shown in the middle table of Fig. 5. Finally, for a given day-of-week-time combination, the largest volume draw is chosen, which is shown in the right-most table in Fig. 5. So the algorithm predicts that on Friday at 5:15 a.m. a draw of 9.5 gal will occur.

Flow data from a real home were used to do a sensitivity analysis on the flow metadata. It was found that time of day (hourly) and a weekday/weekend Boolean variable were best for predicting water flow. Also, flow data were rounded to the nearest 5 gal increment before being input into the GSPS program to help clustering of the data into occurrence/probability bins. A historical window of 42 days was used to predict the water volume draws each hour for the upcoming day.

Flow data from this real house were used as described above and analyzed for how well they predicted hours when flow was 20 gal or more. Figure 6 shows actual draws (rounded to the nearest 5 gal increment) when hourly volume is $20 \mathrm{gal}$ or more. These are the flow events of interest as it is during these large flow events that resistance heat use is most likely to occur. Notice that the forecasting algorithm misses many of these events and predicts 0 gal for most of them. A few events are predicted correctly, and most that are predicted are lower than the actual flows. The CV-RMSE of $\pm 86 \%$ (NMBE of $-73 \%$ ) was computed for how well the algorithm predicted large flow events ( 20 gal or more) for this home for a period of 311 days. This poor prediction accuracy is not indicative of all homes, as will be seen later, and is a function of how regular a household's hot water use is. 


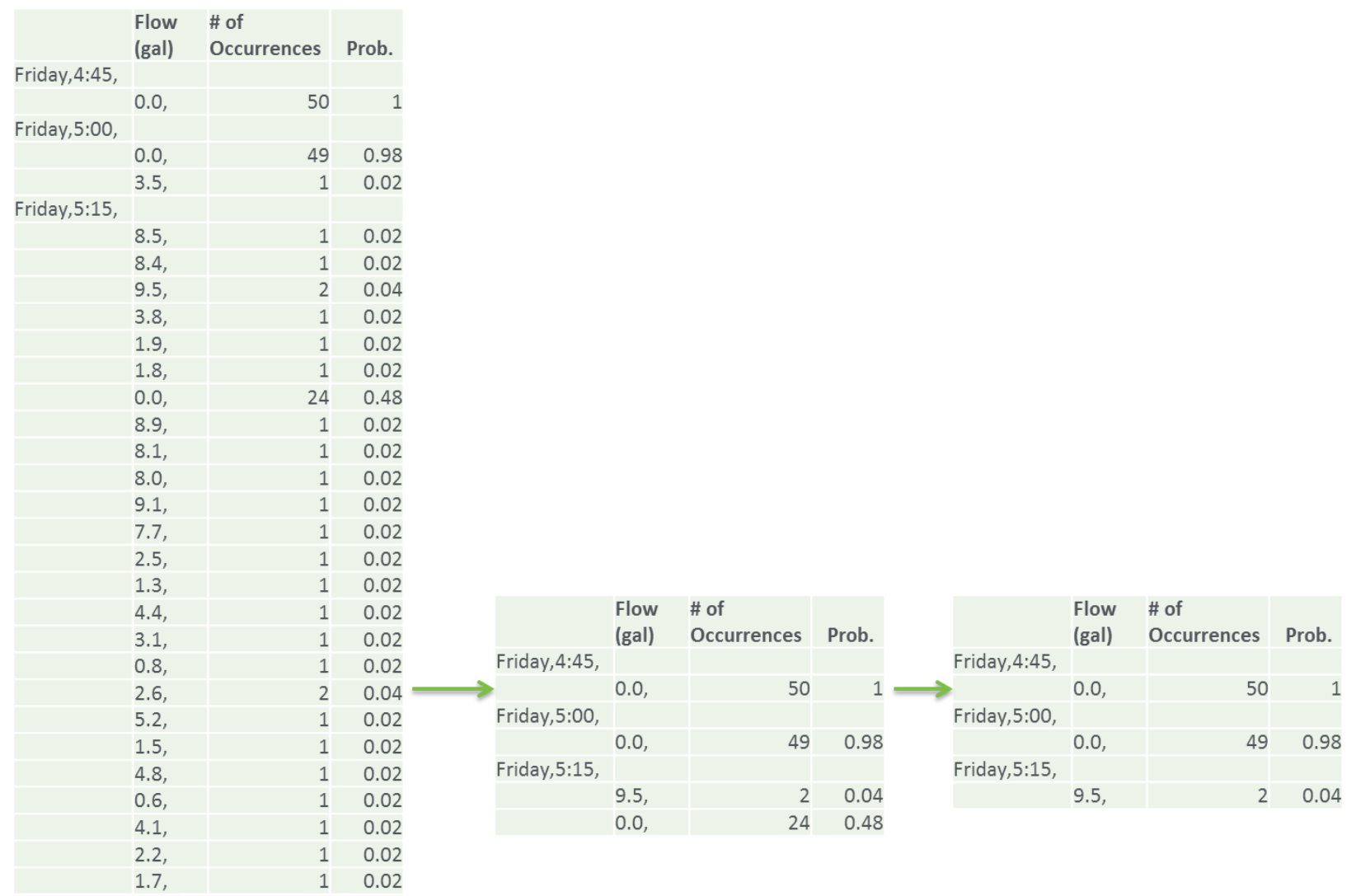

Fig. 5. Example of General Systems Problem Solver data flow.

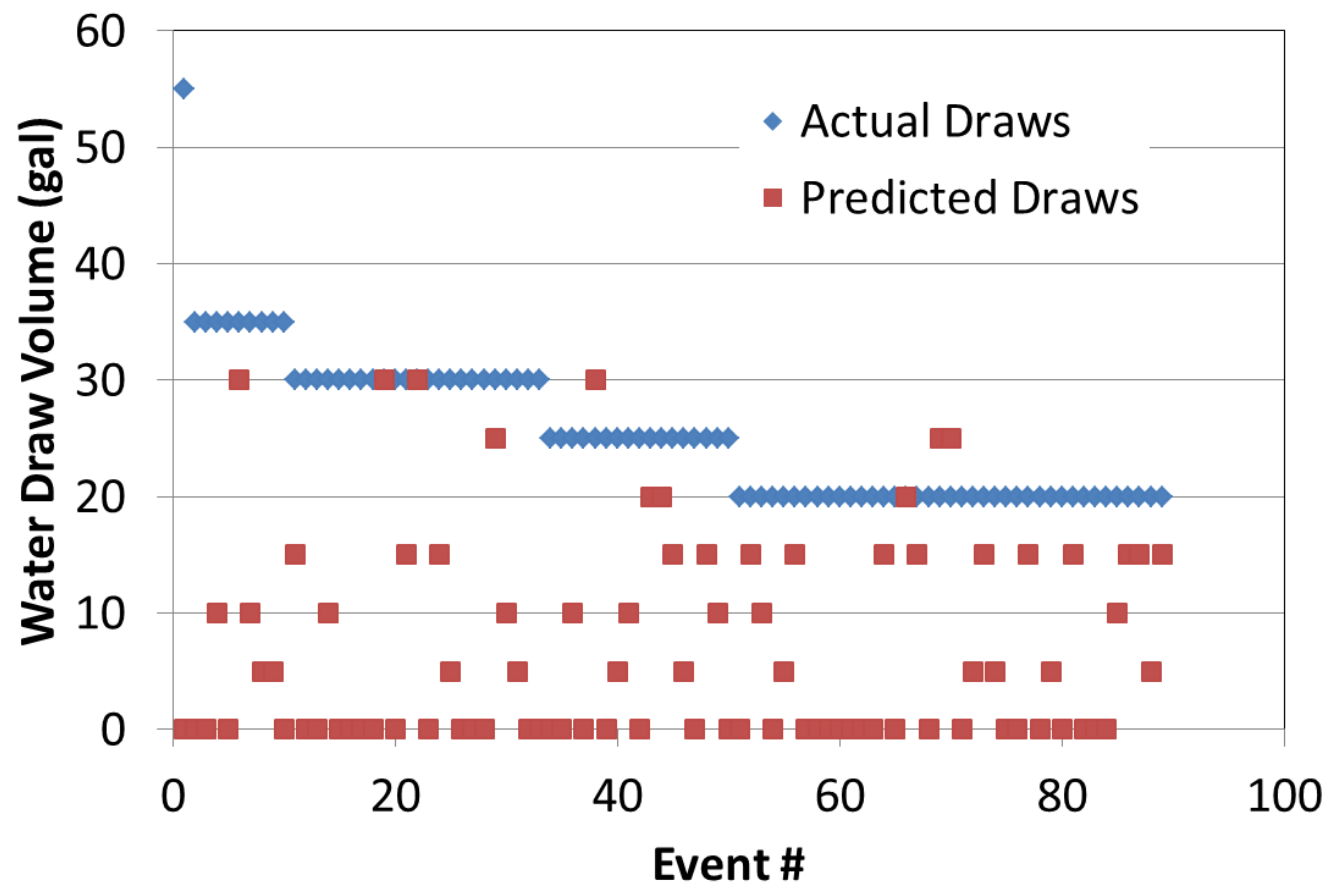

Fig. 6. Actual and predicted hourly flow when 20 gal or more. Plot does not show prediction comparisons when the actual flow was below 20 gal. 


\subsubsection{Temperature Set-Point Algorithm}

The second part of the advanced control algorithm is a set of formulas to decide by how many degrees and for how long the temperature set point $\left(T_{\text {set }}\right)$ should be adjusted to avoid using electric resistance energy. Because large water draws are what typically trigger the use of resistance heat, only draws of 20 gal or more will be targeted by this algorithm. If the predicted water draw for an hour is less than $20 \mathrm{gal}$, then no action is taken and $T_{\text {set }}$ remains at $120^{\circ} \mathrm{F}$. For each hour in the prediction for the upcoming day that the water draw volume is 20 gal or more, the following happens.

First, the new $T_{\text {set }}$ is computed by setting the energy in the volume of water drawn from the tank above the 20 gal threshold to the energy added to the tank if the set point is raised to a temperature higher than $T_{\text {set }}$ called $T_{\text {set,new. }}$. This is represented by the following formula, where $\Delta V$ equals the water flow volume minus 20 gal. Again, this formula is only used when the water draw for an hour is above 20 gal so that a higher temperature set point can be computed; otherwise the temperature set point remains at $120^{\circ} \mathrm{F}$.

$$
\Delta V * 8.34 *\left(T_{\text {set }}-T_{\text {cold }}\right)=V_{\text {tank }} * 8.34 *\left(T_{\text {set }, \text { new }}-T_{\text {set }}\right)
$$

If $T_{\text {set }}$ is equal to $120^{\circ} \mathrm{F}$, then solving the above equation for $T_{\text {set,new }}$ yields the equation below. Due to the model of water heater under test, $T_{\text {set,new }}$ has a maximum value of $170^{\circ} \mathrm{F}$.

$$
T_{\text {set, new }}=\frac{\Delta V\left(120-T_{\text {cold }}\right)}{V_{\text {tank }}}+120
$$

Because the heat pump is used to raise the tank to the new set-point temperature with an estimated heat rate of 4,000 Btu/h, the number of hours that the heat pump needs to turn on before the large flow event occurs can be calculated as shown in the equation below. When the tank temperature is raised above $120^{\circ} \mathrm{F}$, the unit is switched from hybrid mode (where it can use the heat pump or the electric resistance elements) to heat pump only mode. Figure 7 shows the flow diagram for the temperature set-point algorithm.

$$
\Delta t(h r)=\frac{V_{\text {tank }} * 8.34 *\left(T_{\text {set }, \text { new }}-T_{\text {set }}\right)}{4,000}
$$

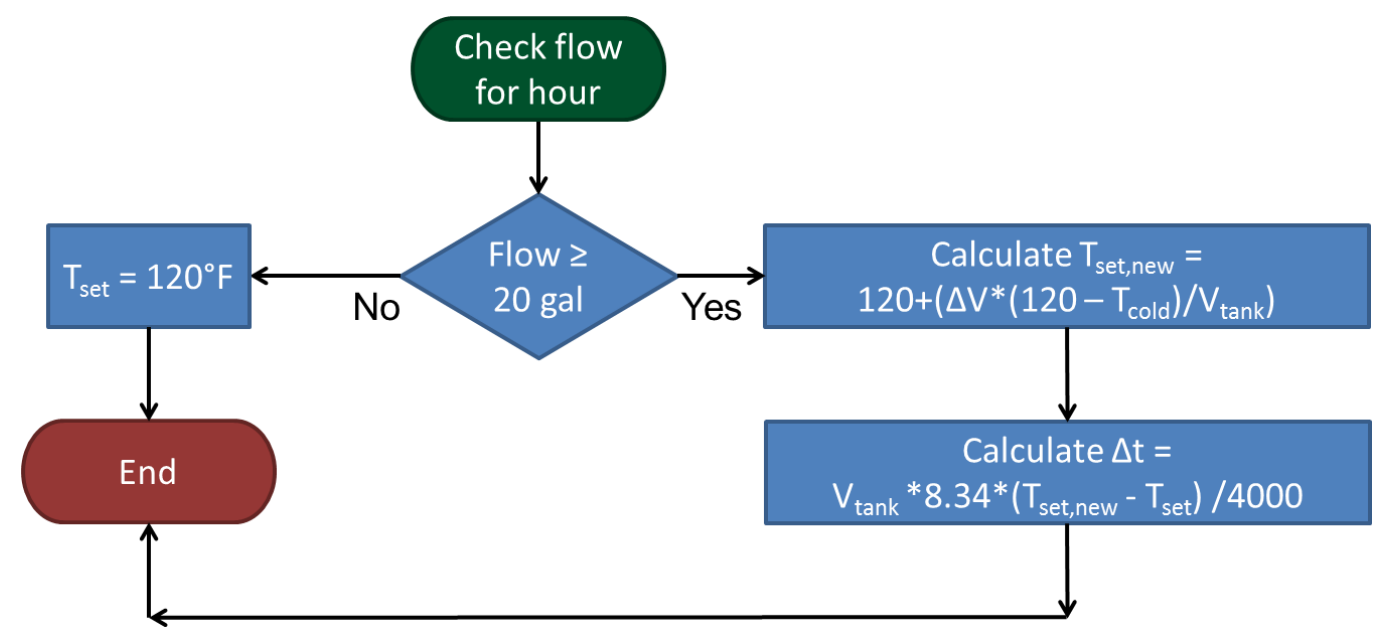

Fig. 7. Logic flow diagram to determine $T_{\text {set,new }}$. 
For each hour's flow, $T_{\text {set,new }}$ (rounded to the nearest $5^{\circ} \mathrm{F}$ ) and $\Delta t$ (rounded to the nearest hour) are computed. From these results a 24 by 24 matrix is created with an individual temperature schedule for each hour, assuming that is the only hour with flow during the day. Figure 8 shows an example of this. To combine the individual schedules (columns), the maximum temperature set point for each hour (rows) is chosen, resulting in a final hourly temperature set-point array for the upcoming day based on the forecasted hourly flows. Figure 8 shows the forecasted hourly flows and the resulting 24 by 24 matrix with the final temperature set-point schedule. For the sake of brevity, most of the hours with no temperature "set-ups" are hidden in Fig. 8. Also notice that the schedule increases the water temperature up to $170^{\circ} \mathrm{F}$. This is a feature of the units available to ORNL to test. A mixing valve was installed after the HPWH to temper the hot water down to $120^{\circ} \mathrm{F}$.

\begin{tabular}{|c|c|c|c|c|c|c|c|c|c|c|}
\hline $\begin{array}{l}\text { Hour of } \\
\text { Day }\end{array}$ & $\begin{array}{l}\text { Forecated } \\
\text { Flow }\end{array}$ & $T_{\text {set, new }}$ & $\Delta \mathrm{t}$ & Hour 1 & Hour 8 & Hour 15 & Hour 16 & Hour 19 & Hour 20 & $\begin{array}{l}\text { Final } \\
\text { Temperature } \\
\text { Set-point } \\
\text { Schedule }\end{array}$ \\
\hline 1 & 0 & 120 & 0 & 120 & 120 & 120 & 120 & 120 & 120 & 120 \\
\hline 2 & 0 & 120 & 0 & 120 & 120 & 120 & 120 & 120 & 120 & 120 \\
\hline 3 & 0 & 120 & 0 & 120 & 120 & 120 & 120 & 120 & 120 & 120 \\
\hline 4 & 0 & 120 & 0 & 120 & 120 & 120 & 120 & 120 & 120 & 120 \\
\hline 5 & 0 & 120 & 0 & 120 & 150 & 120 & 120 & 120 & 120 & 150 \\
\hline 6 & 10 & 120 & 0 & 120 & 150 & 120 & 120 & 120 & 120 & 150 \\
\hline 7 & 0 & 120 & 0 & 120 & 150 & 120 & 120 & 120 & 120 & 150 \\
\hline 8 & 25 & 150 & 4 & 120 & 150 & 120 & 120 & 120 & 120 & 150 \\
\hline 9 & 10 & 120 & 0 & 120 & 120 & 120 & 120 & 120 & 120 & 120 \\
\hline 10 & 0 & 120 & 0 & 120 & 120 & 120 & 120 & 120 & 120 & 120 \\
\hline 11 & 5 & 120 & 0 & 120 & 120 & 120 & 170 & 120 & 120 & 170 \\
\hline 12 & 5 & 120 & 0 & 120 & 120 & 120 & 170 & 120 & 120 & 170 \\
\hline 13 & 10 & 120 & 0 & 120 & 120 & 145 & 170 & 120 & 120 & 170 \\
\hline 14 & 0 & 120 & 0 & 120 & 120 & 145 & 170 & 120 & 120 & 170 \\
\hline 15 & 20 & 145 & 3 & 120 & 120 & 145 & 170 & 120 & 120 & 170 \\
\hline 16 & 40 & 170 & 6 & 120 & 120 & 120 & 170 & 120 & 120 & 170 \\
\hline 17 & 15 & 120 & 0 & 120 & 120 & 120 & 120 & 145 & 120 & 145 \\
\hline 18 & 0 & 120 & 0 & 120 & 120 & 120 & 120 & 145 & 120 & 145 \\
\hline 19 & 20 & 145 & 3 & 120 & 120 & 120 & 120 & 145 & 120 & 145 \\
\hline 20 & 15 & 120 & 0 & 120 & 120 & 120 & 120 & 120 & 120 & 120 \\
\hline 21 & 0 & 120 & 0 & 120 & 120 & 120 & 120 & 120 & 120 & 120 \\
\hline 22 & 10 & 120 & 0 & 120 & 120 & 120 & 120 & 120 & 120 & 120 \\
\hline 23 & 0 & 120 & 0 & 120 & 120 & 120 & 120 & 120 & 120 & 120 \\
\hline 24 & 0 & 120 & 0 & 120 & 120 & 120 & 120 & 120 & 120 & 120 \\
\hline
\end{tabular}

Fig. 8. Illustration of how the final temperature set-point schedule is computed. For the sake of brevity most of the hours with no temperature set-ups are hidden.

\section{RESULTS}

\subsection{INITIAL TESTING OF ADVANCED CONTROL ALGORITHM USING COMPUTER SIMULATIONS}

The forecasting and temperature set-point algorithm were both combined with the HPWH model presented above so that computer simulations could be done to determine the potential energy savings of the advanced control strategy. 
Initial testing of the simulation was done on the same flow data shown in Fig. 6. The simulation was run three times, once without the advanced control algorithm to get a baseline energy consumption, once with the advanced control algorithm turned on, and once with perfect knowledge of the flow events. This perfect forecast was used to determine the best case scenario: if the forecasting algorithm predicted all large flow events then how much energy could be saved? Analysis of the data included computing different metrics such as energy consumption, electric resistance energy use, and hot water quality. The hot water quality is the number of hours that the hot water temperature is below $115^{\circ} \mathrm{F}$. Table 1 shows these results as well as the forecasting CV-RMSE. This is computed by comparing the perfect knowledge flow events of 20 gal and above to the predicted flow events for those hours. Notice that hardly any energy was saved for the test house with the forecasting algorithm, which is due to the poor prediction accuracy. The algorithm only predicted three large water draw events (out of 88) correctly. However if the forecasting algorithm had predicted all the large draws, then an energy savings greater than 14\% would have been achieved. This shows that the temperature set-point algorithm is working well and that a possible weak point in the advanced control algorithm is the forecasting routine. The weak point however could be due to a lack of predictability in the large water draw patterns of the home instead of an issue with the forecasting algorithm itself.

Table 1. Results from initial testing of advanced control algorithm on one home

\begin{tabular}{cccccc}
\hline & Baseline & $\begin{array}{c}\text { Advanced } \\
\text { Control }\end{array}$ & Perfect & $\begin{array}{c}\text { Forecast } \\
\text { Savings }\end{array}$ & Perfect Savings \\
\hline Total Energy (kWh) & 518.3 & 517.3 & 442.9 & $0.2 \%$ & $14.5 \%$ \\
$\begin{array}{c}\text { Electric Res. Energy } \\
(\mathbf{k W h})\end{array}$ & 157.9 & 126.7 & 8.4 & $19.8 \%$ & $94.7 \%$ \\
$\begin{array}{c}\text { Hours under 115 } \mathbf{F}^{\circ} \\
\text { Forecast CV-RMSE } \\
(\mathbf{N M B E})\end{array}$ & 560.8 & 709.9 & 436.2 & $-26.6 \%$ & $22.2 \%$ \\
\hline
\end{tabular}

According to the results shown in Fig. 6, there were a few times where the prediction algorithm correctly predicted a large flow event. One of those instances was on May 10th. Figure 9 shows the results of the baseline simulation on May 10th for the test home. Notice that the large 30 gal flow event (over 1 hour) caused the electric resistance heat to come on. The energy consumption for this day was $3.7 \mathrm{kWh}$. Figure 10 shows the same day with the advanced control algorithm implemented. Notice that there is no electric resistance energy consumption and the temperature set-point algorithm raised the set point to $140^{\circ} \mathrm{F}$ from 3:00 p.m. to 6:00 p.m. With the advanced control algorithm the daily energy use was $1.6 \mathrm{kWh}$ - more than a 50\% energy savings over the baseline. This savings is due to the 3-hour temperature set-point set-up as well as the carryover afforded from a temperature set-point set-up the previous day. While this is substantial, the advanced control algorithm predicted many high volume flow events that didn't actually occur. On these days the advanced control algorithm caused higher energy consumption over the baseline. This is why, for this home; the energy savings were not significant. However, as shown in the analysis to follow, the energy savings are specific to the hot water consumption patterns of each home. We expect, and verify in the following section, that the savings are greater for most homes. 


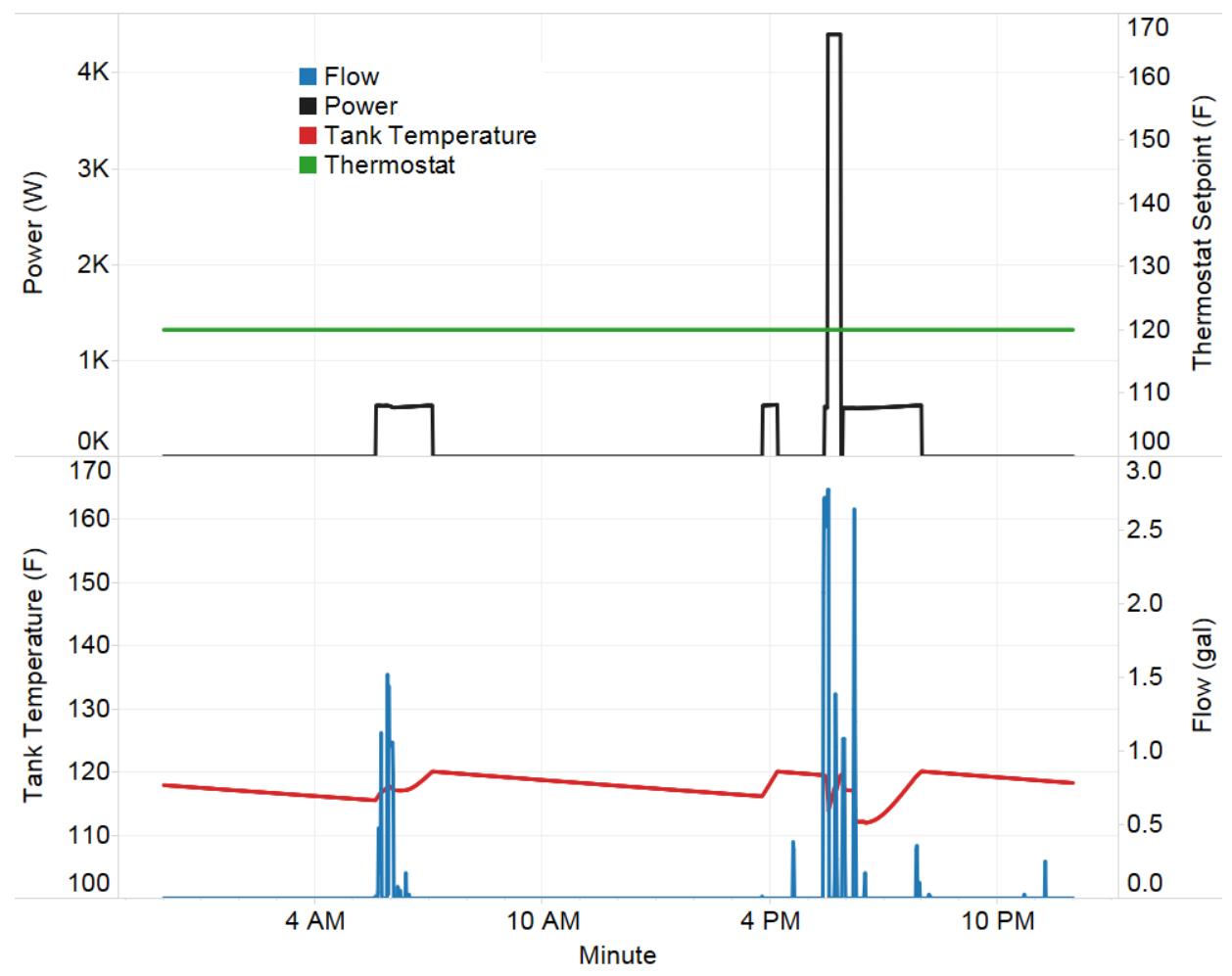

Fig. 9. Baseline simulation results for one home on May 10th.

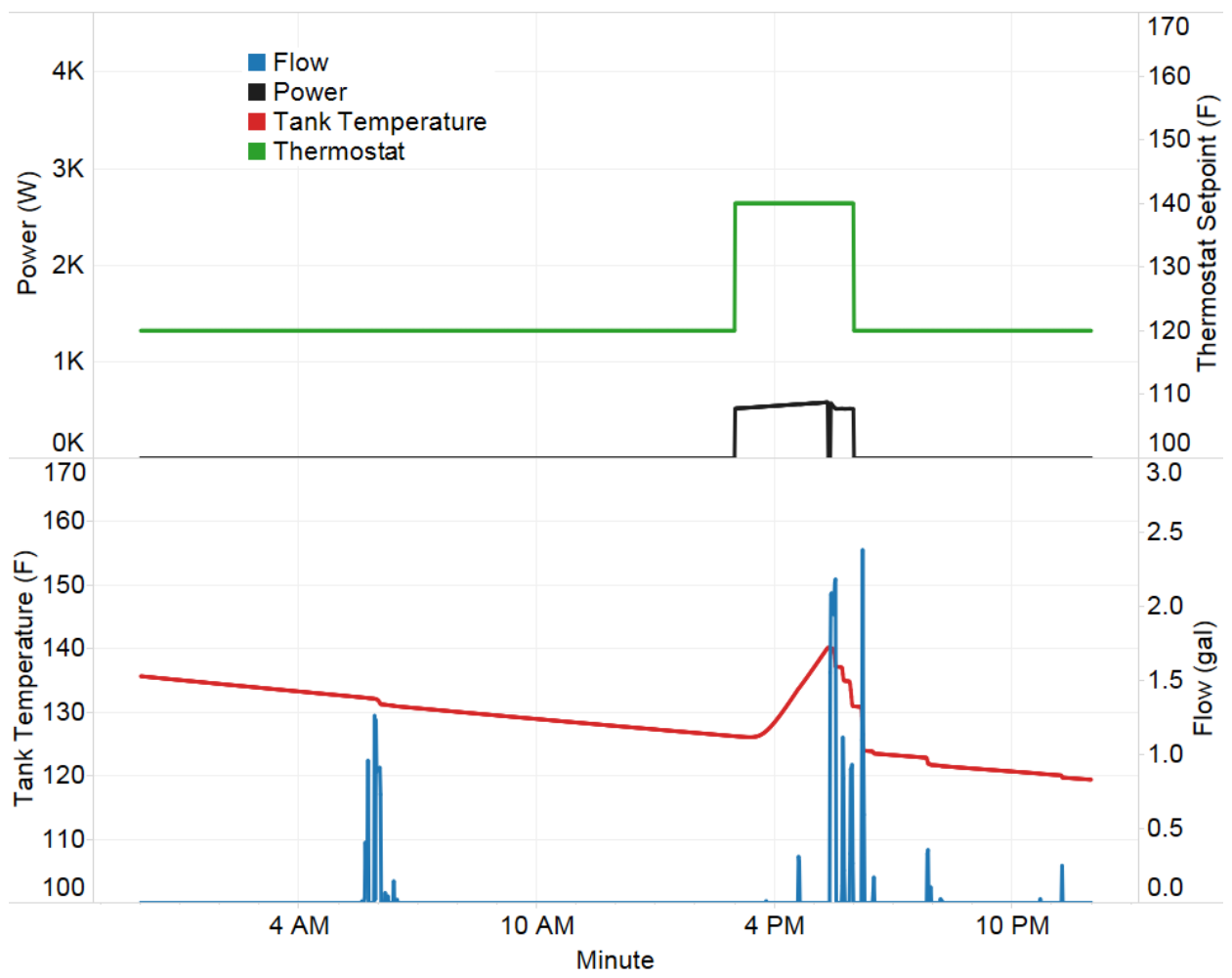

Fig. 10. Advanced control algorithm simulation results for one home on May 10th. 


\subsection{ANALYSIS OF 25 HOMES FOR HPWH SAVING USING THE ORNL ADVANCED CONTROL ALGORITHM}

To get a better idea of how well the advanced control algorithm performs, a set of 25 homes was tested. These homes had 1 min data for hot water flow, ambient temperature, and incoming cold water temperature for at least 1 year. Just as with the test home described previously, each home was put through the simulation three times, for a baseline, advanced control algorithm, and perfect prediction result. Because the methods and conditions differ, the reported baseline results are not comparable to rated product performance and should only be used to estimate performance under the modeled condition. Figure 11 shows the average energy consumption for the baseline, advanced control, and perfect prediction cases. Notice that the advanced control yields savings on average but does not meet the perfect prediction case. The energy savings of the advanced control and perfect prediction cases are shown in Table 2. Home specific results similar to Table 1 are presented in Appendix A.

\section{Energy Consumption}

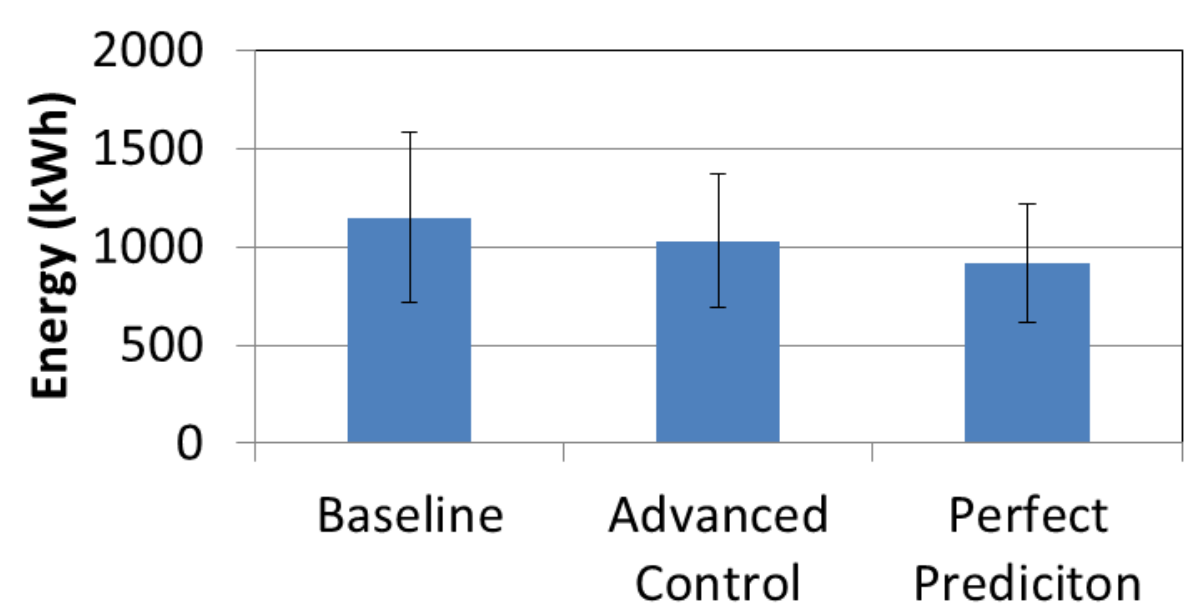

Fig. 11. Average energy consumption of the baseline, advanced control, and perfect prediction cases for a set of 25 homes.

Table 2. Statistics of 25-home study

\begin{tabular}{cccc}
\hline & $\begin{array}{c}\text { Advanced Control } \\
\text { Savings }\end{array}$ & $\begin{array}{c}\text { Perfect Prediction } \\
\text { Savings }\end{array}$ & CV-RMSE of Forecast \\
\hline Average & $8.9 \%$ & $18.5 \%$ & $\pm 67.1 \%$ \\
Standard Deviation & $7.4 \%$ & $8.2 \%$ & $\pm 11.8 \%$ \\
Minimum & $-0.8 \%$ & $3.9 \%$ & $\pm 52.2 \%$ \\
Maximum & $24.4 \%$ & $39.5 \%$ & $\pm 91.7 \%$ \\
\hline
\end{tabular}

Figure 12 shows histograms of energy savings for both the advanced control algorithm and the perfect prediction cases and a histogram of electric resistance energy savings for the advanced control algorithm. The majority of the savings for the perfect prediction are between $20 \%$ and $25 \%$. The two largest bins for the forecasting algorithm case are split on either side of the average savings bin at $0-5 \%$ and $10 \%-15 \%$. The average energy savings for resistance heat was $50 \%$ for the advanced algorithm, with the largest bin of savings being $60 \%-70 \%$. 
Advanced Control

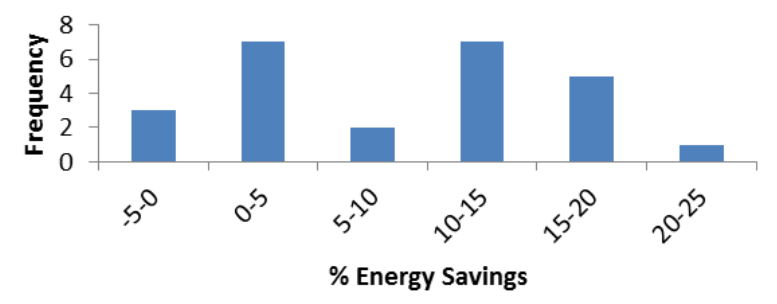

Perfect Prediction

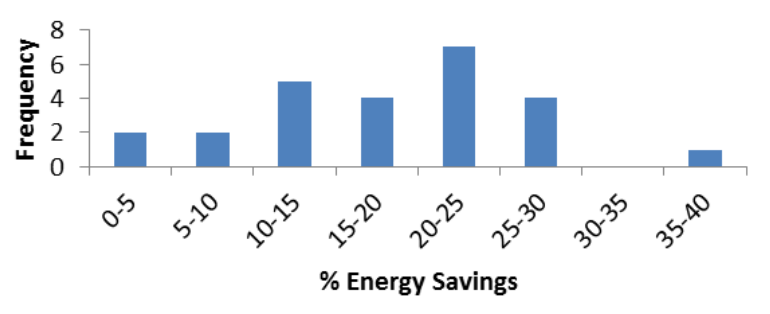

\section{Advanced Control}

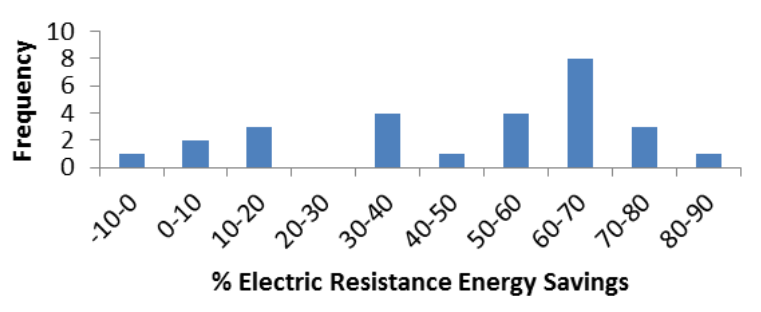

Fig. 12. Histogram of advanced control algorithm (forecasted) energy savings results compared to perfect prediction energy savings results. Also shown is the electric resistance energy savings for the advanced control algorithm.

The correlation of energy savings to forecasting uncertainty (CV-RMSE) and baseline electric resistance heat are shown and discussed below.

Figure 13 shows the energy savings plotted against CV-RMSE. Although no definite trend is seen in this data, there is a definite CV-RMSE above which no significant savings are realized. Figure 12 shows that this is around $75 \%$, where below the forecasting uncertainty of $75 \%$ the savings are typically higher than if the forecasting uncertainty is above $75 \%$. This shows that greater savings are likely when the large water flow events are more predictable. It also shows that the predictability of large water flow events varies widely by household.

Figure 14 shows the correlation between baseline electric resistance heater use and advanced control algorithm energy savings. These variables correlate much better than CV-RMSE and energy savings. Electric resistance heat use is a good indication of large water draws, and so the higher the electric resistance heat use, the more potential for savings using the advanced control algorithm. Given that reducing the use of electric resistance water heating is a primary goal of the advanced control algorithm it was expected that the savings would be correlated to resistance heater use. 


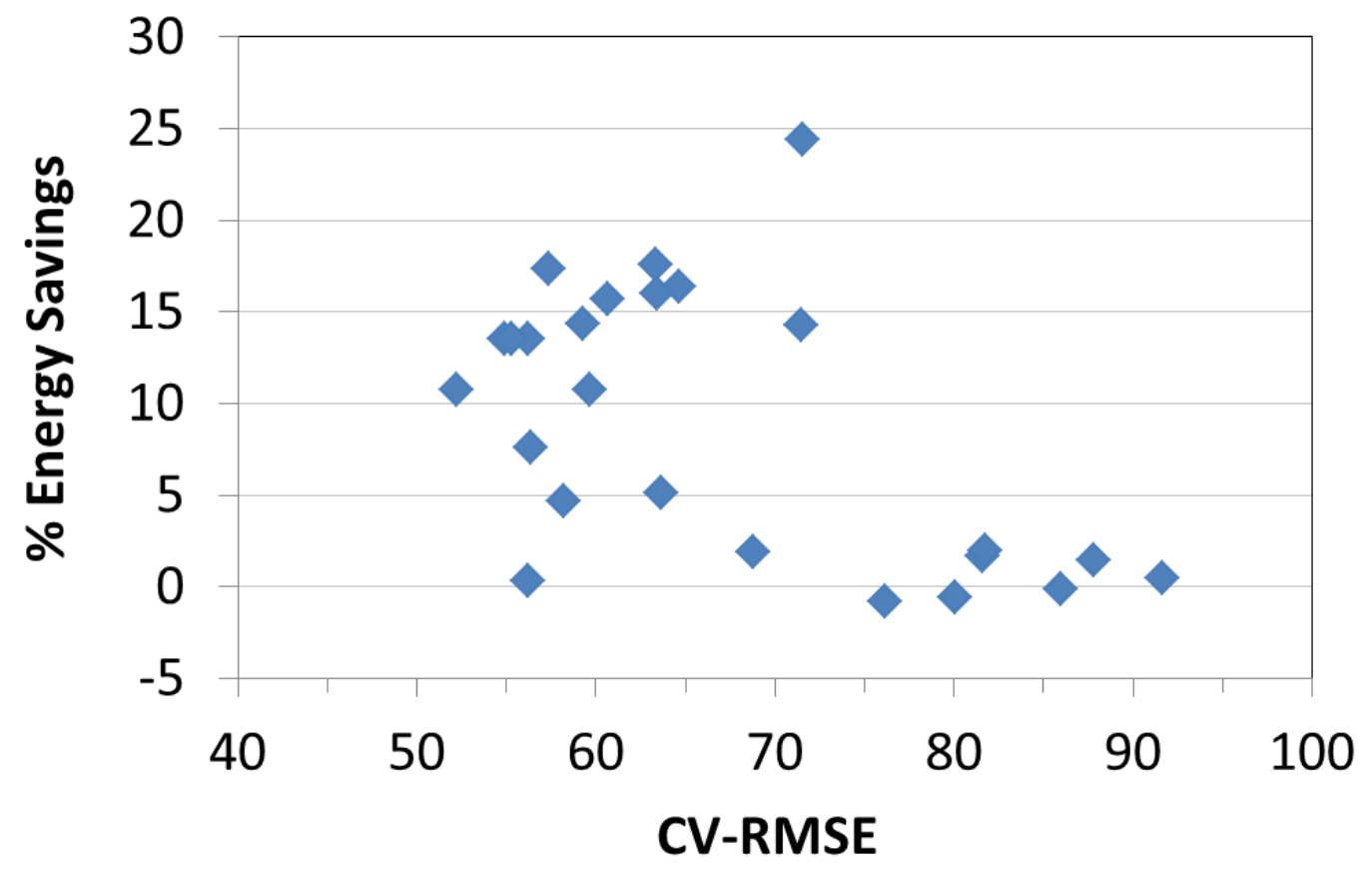

Fig. 13. Advanced control algorithm energy savings plotted as a function of the coefficient of variation of the root mean square error (CV-RMSE) of forecasted water draw volume.

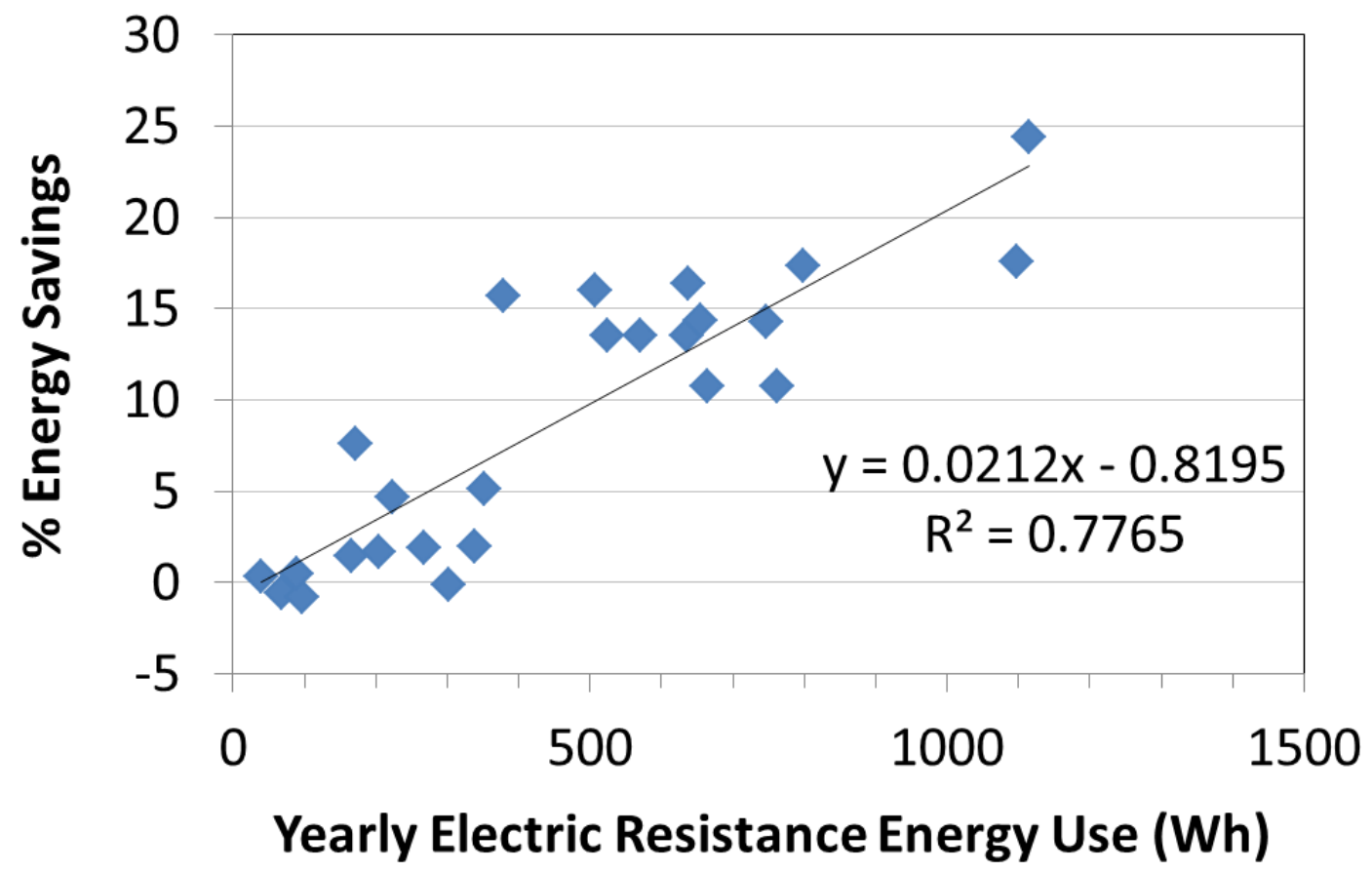

Fig. 14. Advanced control algorithm savings plotted as a function of baseline yearly electric resistance energy consumption. 
It was expected that the advanced control algorithm would increase the hot water quality (i.e., decrease the time that hot water in the tank was below $115^{\circ} \mathrm{F}$ ) because during high water draw events the tank water would be warmer when the advanced control algorithm was in effect. It turns out that these results vary widely by home. Sometimes the advanced control algorithm yields higher water quality and sometimes lower, such that on average there is no statistical difference in water quality between the baseline and set-up schedules.

\section{CONCLUSION}

A team of ORNL researchers investigated the use of an advanced control algorithm to minimize electric resistance heater use in HPWHs to increase the energy efficiency of the units. The advanced control algorithm predicts water consumption for the upcoming day on an hourly basis based on historical data. For hours that have water draws that total 20 gal or more, the algorithm sets the temperature set point of the tank up a calculated number of hours before the anticipated large water draw to store enough thermal energy in the tank that electric resistance heat is not needed.

The advanced control algorithm was tested with a validated HPWH model. Simulations of 25 homes showed that the advanced control algorithm saved an average of about $9 \%$ over the baseline case, where the unit was kept at a flat $120^{\circ} \mathrm{F}$ set point. Water heating energy for these homes was also simulated with the advanced control algorithm, assuming that the water draw forecasting algorithm perfectly predicted future draws that were 20 gal or more. In this case the average savings was $19 \%$. This would be the best case scenario and could mean that improvements could be made to the forecasting algorithm or that some homeowners don't have a predictable enough draw pattern for this technique to offer any energy savings benefit.

More research can be done to improve the forecasting algorithm and to possibly auto-tune the algorithm for specific homes. It could be that not all homes work best with the independent prediction variables used in this study (time of day and a weekday/weekend Boolean). Furthermore, study of the predictability of hot water use occupancy patterns should be studied. If a household has an inconsistent hot water use pattern, then the advanced control algorithm presented here could increase the energy consumption of the HPWH.

\section{REFERENCES}

ASHRAE. 2002. Measurement of Energy Savings and Demand Savings. Guideline 14-2002, American Society of Heating, Refrigerating and Air-Conditioning Engineers, Inc., Atlanta, Georgia.

Boudreaux, P., K. Biswas, and R. Jackson. 2013. Advancing Residential Retrofits in the Mixed-Humid Climate to Achieve Deep Energy Savings: Final Report on Knoxville, Tennessee, Homes. ORNL/TM2012/533, Oak Ridge National Laboratory, Oak Ridge, Tennessee.

BTP. 2012. 2011 Buildings Energy Data Book. US Department of Energy, Office of Energy Efficiency and Renewable Energy, Building Technologies Program, Washington, DC.

Christian, J., T. Gehl, P. Boudreaux, J. New, and R. Dockery. 2010. Tennessee Valley Authority's Campbell Creek Energy Efficient Homes Project: 2010 First Year Performance Report July 1, 2009 August 31, 2010. ORNL/TM-2010/206, Oak Ridge National Laboratory, Oak Ridge, Tennessee. 
Hudon, K., B. Sparn, D. Christensen, and J. Maquire. 2012. Heat Pump Water Heater Technology Assessment Based on Laboratory Research and Energy Simulation Models. NREL/CP-5500-51433, National Renewable Energy Laboratory, Golden, Colorado.

Klir, G., and D. Elias. 2003. Architecture of Systems Problem Solving, 2nd edition, Kluwer Academic/Plenum Publishers.

Larson, B., and M. Logsdon. 2013. "Heat Pump Water Heater-Quick Simulation Approach." Presented at the 2013 ACEEE Hot Water Forum, November 3-5, 2013, Atlanta, Georgia. American Council for an Energy-Efficient Economy, Washington, DC. 

APPENDIX A. RESULTS FROM 25-HOME STUDY 



\section{APPENDIX A. RESULTS FROM 25-HOME STUDY}

\begin{tabular}{|c|c|c|c|c|c|c|c|c|c|c|c|c|c|c|}
\hline \multirow[b]{2}{*}{ Site \# } & \multicolumn{2}{|c|}{ Baseline } & \multicolumn{2}{|c|}{ Forecast } & \multicolumn{2}{|c|}{ Perfect } & \multicolumn{4}{|c|}{ Energy savings } & \multicolumn{4}{|c|}{ Prediction Statistics } \\
\hline & $\begin{array}{l}\text { Total Energy } \\
(\mathrm{kWh})\end{array}$ & $\begin{array}{l}\text { Res Heat } \\
\text { Energy (kWh) }\end{array}$ & $\begin{array}{l}\text { Total Energy } \\
\text { (kWh) }\end{array}$ & $\begin{array}{l}\text { Res Heat } \\
\text { Energy (kWh) }\end{array}$ & $\begin{array}{l}\text { Total Energy } \\
\text { (kWh) }\end{array}$ & $\begin{array}{l}\text { Res Heat } \\
\text { Energy (kWh) }\end{array}$ & $\begin{array}{l}\text { Forecast } \\
\text { Total } \\
\text { Energy }\end{array}$ & $\begin{array}{l}\text { Perfect } \\
\text { Total } \\
\text { Energy }\end{array}$ & $\begin{array}{l}\text { Forecast } \\
\text { Res. Heat } \\
\text { Energy }\end{array}$ & $\begin{array}{l}\text { Perfect } \\
\text { Res. Heat } \\
\text { Energy }\end{array}$ & CVRMSE & NMBE & $\begin{array}{l}\text { \# of large } \\
\text { flow events }\end{array}$ & $\begin{array}{l}\text { \# of large flow } \\
\text { events predicted } \\
\text { correctly }\end{array}$ \\
\hline 99065 & 1386.2 & 638 & 1159.6 & 193.7 & 1037 & 31.1 & $16 \%$ & $25 \%$ & $70 \%$ & $95 \%$ & 64.79132 & -43.1237 & 260 & 46 \\
\hline 99086 & 1440.7 & 747 & 1234.9 & 308.5 & 1050.8 & 44.3 & $14 \%$ & $27 \%$ & $59 \%$ & $94 \%$ & 71.56875 & -51.2639 & 307 & 48 \\
\hline 99087 & 771.5 & 204.5 & 758.6 & 172.7 & 654.4 & 3.6 & $2 \%$ & $15 \%$ & $16 \%$ & $98 \%$ & 82.02625 & -73.2602 & 96 & 3 \\
\hline 99088 & 1123.1 & 506.5 & 943.2 & 135.5 & 865.3 & 47.9 & $16 \%$ & $23 \%$ & $73 \%$ & $91 \%$ & 63.56548 & -30.5986 & 182 & 23 \\
\hline '99094 & 1579.6 & 635.2 & 1365.6 & 194 & 1275.9 & 108.2 & $14 \%$ & $19 \%$ & $69 \%$ & $83 \%$ & 56.33662 & -30.6154 & 243 & 67 \\
\hline 99095 & 656.8 & 166.4 & 647.1 & 139.8 & 564.3 & 14 & $1 \%$ & $14 \%$ & $16 \%$ & $92 \%$ & 88.3642 & -83.4365 & 78 & 1 \\
\hline '99096 & 1711.3 & 798.1 & 1413.8 & 204.9 & 1290.4 & 27 & $17 \%$ & $25 \%$ & $74 \%$ & $97 \%$ & 57.43726 & -16.8348 & 345 & 41 \\
\hline 99097 & 1993.4 & 1098.3 & 1643.2 & 383.9 & 1457.2 & 169.3 & $18 \%$ & $27 \%$ & $65 \%$ & $85 \%$ & 63.46625 & -37.6186 & 359 & 46 \\
\hline '99098 & 1653.5 & 762.2 & 1475.3 & 315 & 1266.8 & 77.2 & $11 \%$ & $23 \%$ & $59 \%$ & $90 \%$ & 59.72441 & -33.4633 & 311 & 43 \\
\hline 99100 & 1044 & 266.6 & 1024.5 & 180 & 911.4 & 16.4 & $2 \%$ & $13 \%$ & $32 \%$ & $94 \%$ & 69.03432 & -53.3453 & 133 & 8 \\
\hline 99101 & 708.9 & 68.8 & 712.8 & 70.1 & 681 & 12.3 & $-1 \%$ & $4 \%$ & $-2 \%$ & $82 \%$ & 80.93833 & -76.3571 & 49 & 2 \\
\hline 99102 & 1562.2 & 1115.3 & 1181.5 & 354 & 944.4 & 29.1 & $24 \%$ & $40 \%$ & $68 \%$ & $97 \%$ & 71.62236 & -46.0429 & 331 & 26 \\
\hline 99103 & 762.3 & 97.1 & 768.6 & 88.6 & 710.4 & 4.5 & $-1 \%$ & $7 \%$ & $9 \%$ & $95 \%$ & 76.59366 & -67.3849 & 84 & 10 \\
\hline 99104 & 616.7 & 89.5 & 613.9 & 85.3 & 561.3 & 10.3 & $0 \%$ & $9 \%$ & $5 \%$ & $88 \%$ & 92.9348 & -86.2694 & 38 & 0 \\
\hline 99107 & 1361.8 & 654 & 1166.1 & 183.2 & 1011.8 & 28.8 & $14 \%$ & $26 \%$ & $72 \%$ & $96 \%$ & 59.36534 & -35.1136 & 284 & 41 \\
\hline 99108 & 866.6 & 378.2 & 730.4 & 113.5 & 674.8 & 43.9 & $16 \%$ & $22 \%$ & $70 \%$ & $88 \%$ & 60.89178 & -32.6881 & 148 & 18 \\
\hline 99118 & 747.4 & 301.7 & 748.5 & 269.9 & 585.7 & 27.5 & $0 \%$ & $22 \%$ & $11 \%$ & $91 \%$ & 86.34698 & -77.0843 & 109 & 6 \\
\hline 99119 & 1100.5 & 351.2 & 1044.2 & 211.3 & 930.4 & 57 & $5 \%$ & $15 \%$ & $40 \%$ & $84 \%$ & 63.82316 & -48.8771 & 159 & 17 \\
\hline 99122 & 1396.6 & 570.4 & 1208.1 & 109.3 & 1084 & 17.4 & $13 \%$ & $22 \%$ & $81 \%$ & $97 \%$ & 55.00508 & -36.583 & 263 & 88 \\
\hline 99123 & 984.8 & 224.2 & 938.8 & 112.5 & 874.2 & 28 & $5 \%$ & $11 \%$ & $50 \%$ & $88 \%$ & 58.40101 & -40.4729 & 144 & 26 \\
\hline 99124 & 1142.8 & 338.4 & 1120.2 & 228.6 & 978.8 & 25.7 & $2 \%$ & $14 \%$ & $32 \%$ & $92 \%$ & 82.05487 & -68.4465 & 139 & 11 \\
\hline 99140 & 642.4 & 171 & 593.6 & 53.6 & 551.8 & 5.5 & $8 \%$ & $14 \%$ & $69 \%$ & $97 \%$ & 56.6552 & -24.1141 & 107 & 26 \\
\hline 99150 & 475.4 & 40.2 & 473.7 & 18.6 & 454.5 & 0 & $0 \%$ & $4 \%$ & $54 \%$ & $100 \%$ & 56.74304 & -29.3858 & 58 & 26 \\
\hline 99155 & 1831.1 & 664.2 & 1634.9 & 214.7 & 1477.3 & 41.2 & $11 \%$ & $19 \%$ & $68 \%$ & $94 \%$ & 52.29543 & -30.8147 & 323 & 47 \\
\hline 99162 & 1278 & 523.8 & 1104.9 & 178.6 & 1006.5 & 56.7 & $14 \%$ & $21 \%$ & $66 \%$ & $89 \%$ & 55.44878 & -18.764 & 228 & 32 \\
\hline
\end{tabular}

Fig. A-1. Energy savings and prediction statistics for 25-house study. 
